\title{
Decentralized Health Service Delivery System in Bangladesh: Evaluating Community Clinics in Promoting Healthcare for the Rural Poor
}

\author{
Md. Assraf Seddiky, Associate Professor \\ Department of Public Administration Shahjlal University of Science \& \\ Technology, Sylhet Bangladesh PhD researcher (Disaster Management) \\ The University of Newcastle, Australia
}

Doi:10.19044/esj.2020.v16n12p253 URL:http://dx.doi.org/10.19044/esj.2020.v16n12p253

\begin{abstract}
The Awami League government of Bangladesh has established community clinics as decentralized healthcare units at the village level to ensure smooth and equal access to family planning, preventive health services, and limited curative care for the local community. The primary aspiration of this study is to evaluate the dynamics of service delivery systems under decentralized community clinics in rural areas of Bangladesh. It also aims to explore the challenges of accessing healthcare services and the impacts of decentralization on the promotion of the service delivery system of the community clinics. A qualitative field study was conducted in Sylhet District in the northeastern part of Bangladesh to collect the necessary data regarding the study objectives. The respondents were sampled through a purposive sampling method. Data collection was done through in-depth interviews and focus group discussions. The study findings revealed that the aspect of services in community clinics is being questioned due to different sociocultural, political, economic, and administrative stumbling blocks. If the government ensures skilled workforce, structural and technical support, locallevel planning, adequate funding, strategic coordination, and delegation of functions to address the challenges in providing health services to community clinics, then it is believed that these community-knit clinics would be considered as the lighthouse for providing primary healthcare for the disadvantaged rural sections of Bangladesh.
\end{abstract}

Keywords: Decentralization, Healthcare, Service Delivery, Community Clinics, Rural-Poor, Bangladesh 


\section{Introduction}

The need for primary health care and effective preventive health efforts have gained prominence in most developing countries, with a shift in the global health agenda from MDGs (Millennium Development Goals) to SDGs (Sustainable Development Goals) (Ackatia-Armah, Addy, Ghosh, \& Dube, 2016). Health is a part of the capability approach of human beings, which provides a person with the freedom to determine the value of their life (Aminuzzaman, 2010). Therefore, the level of healthcare services could be taken as an important indicator of development for any country. Taking this issue into account, healthcare strategies should be formulated in developing countries based on peoples' aspirations for promoting better accessibility and easier utilization of the public healthcare system (Jana \& Harata, 2016). Community Clinics (CC), in this regard, are providing primary healthcare services to the common people through trained health providers and nurses in both developed and developing countries. It is a tiny rural clinic in Bangladesh for ensuring and promoting health, nutrition and family planning, especially for the treatment of minor diseases, first aid and identification of crunch and intricate cases to facilitate smooth, referral links with Upazila Health Complex (UHC) and Union Family Welfare Center (UFWC). Close to community health care workers is an increasingly used term to describe the role of community-based clinics in health care provisions to the local people (Iyngkaran, Biddargardi, Bastiampillai, \& Beneby, 2015). According to the Ottawa Charter, the effective exercise of community control over health is indispensable to improving health care provisions that emphasize community action and awareness building and thus also promoting the idea of primary health care developed for the community people in local areas (March et al., 2015). It opens a window of opportunity to greater community involvement in primary health services and easy access to the majority of the community.

Most of the people in Bangladesh in rural areas predominantly live on agriculture, and they are therefore subject to states of vulnerability and suffering from severe malnutrition regarding healthcare services. The government of Bangladesh is responsible for providing healthcare services to the people of all social strata as per section 15(A), as well as for developing its citizens' health and nutrition status as per section 18(1) of the Constitution of the Peoples' Republic of Bangladesh (Seddiky, 2019). In order to fulfill these healthcare provisions, the government of Bangladesh decentralized the healthcare system to extend health services to the doorsteps of the ordinary people.

Hence, community clinics are the lowest unit of decentralized health care delivery, each of which serves 6,000 people at the grassroots level in Bangladesh (Islam \& Biswas, 2014). Currently, 13,500 community clinics are 
functioning in rural Bangladesh to serve the rural people (Sultana \& Tania, 2015).

\section{Problem Statement}

Bangladesh is a South Asian small country with one hundred and sixty million populations, and about seventy percent of them live in rural areas (Chowdhury \& Jenkins, 2018). The mission of the decentralized healthcare system in Bangladesh is to strengthen local health care provision, which would allow local people to access better healthcare services through more effective and efficient institutional management (Ahmed et al., 2015). However, as Bangladesh is an emerging country, the government only provides $34 \%$ of total health expenditures, and the remaining $66 \%$ is private expenses (Islam \& Biswas, 2014). Furthermore, only $3.4 \%$ of GDP is spent on health in Bangladesh, and the government contributes only $1.1 \%$, so poor people have to pay more on health throughout- of-pocket payments, as there is no health insurance in Bangladesh (Islam \& Biswas, 2014). Despite having rural healthcare infrastructure, the rural populations do not get better or equal health services due to a shortage of healthcare workforce (Kouam et al., 2014). In most of the community clinics in Bangladesh, staff members are recruited based on political affiliation without consideration of their skills, so they abuse their power and deprive local people of primary healthcare services (Sultana \&Tania, 2015). Corruption and lack of institutional capacity building also undermine the objectives of the community clinics in rural Bangladesh (Hasan, 2012). The government of Bangladesh is committed to guaranteeing equal and basic medical services for all people. However, the rural villagers receive low-quality health service, and they have little or no access to better health care due to the physical proximity of impoverished rural areas (Seddiky, Ara, \& Yasmin, 2014). Considering these issues into account, the Awami League government has decentralized healthcare facilities from urban to rural areas and established community clinics in every ward of the Union Parishad (the lowest tier of local government), intended to ensure primary healthcare services for the common people.

Sylhet is one of the most attractive and archeologically rich regions due to its diverse geographical landscape, i.e., forests, rivers, and hills. There are about 160 tea gardens in this region, and more than 30,000 laborers are working there (Ahmad, Yasin, Rowshon, \& AKM, 2015).

A good number of people in this region have British citizenship, so a handsome amount of remittance comes here from them. Given this economic opportunity, many people migrate here from different parts of Bangladesh (Hossain, Ahmed, \& Rahman, 2017). It is also very close to the Indian border, and many poor refuges from Indian parts enter into this area and live here permanently. Besides, five indigenous ethnic minority groups live in both hilly 
and plain lands of this region (Akter, Mazumder, Alam, Pal, \& Mozahid, 2017). These people are illiterate and impoverished and unable to meet with the doctors in private hospitals. They want easily accessible and cheap treatment facilities. However, very few numbers of community clinics are providing primary healthcare services to almost 12.1 million population of this region.

\section{Objective and Research Questions}

The broad objective of this study is to evaluate the dynamics of service delivery systems under decentralized community clinics in rural areas of Bangladesh.

In order to fulfill the general objective, the study explores the following research questions:

1. What challenges does the community face in terms of accessing the healthcare services of community clinics in rural Bangladesh?

2. What are the different types and qualities of services provided by community clinics, and to what extent do those services meet the healthcare needs of the community's people?

3. What are the impacts of decentralization on the promotion of service delivery provision for the community clinics?

\section{Significance of the Study}

Since the British colonial period, the rural people of Bangladesh have been deprived of better healthcare services, and even after 48 years of independence from Pakistan, the poor are still in a vulnerable healthcare situation. Hence, community clinics provide an opportunity to make a healthenabling community that supports health-promoting behavior by empowering those community members who are particularly susceptible to health problems. It is essential to develop policies for effective primary health care based on addressing the needs of community involvement with limited and unequal access to health services (Ackatia-Armah, Addy, Gosh, \& Dube, 2016). This study aims to assess the performance of community clinics in rural Bangladesh in terms of health care, community views of the problems, and the promotion of policies to provide better health care to this population.

In Bangladesh, the rural health sector has received no considerable amount of academic attention that could contribute to the further development of this problem by way of policy interventions. Although many studies have been conducted on the healthcare issues of the rural poor, focusing on different areas such as family planning, education, adolescent reproductive health status (Bhuiya et al., 2004), utilization of maternal health care (Anwar, Killewo, Chowdhury, \& Dasgupta, 2005), the contribution of community clinics to maternal and childhood health (Islam \& Biswas, 2014), no research has yet 
attempted to examine rural people's accessibility problems for primary healthcare services or the systematic problems of the decentralized health care system from a sociological standpoint. Moreover, the study's findings will hopefully serve as a baseline for future researchers and academics, opening up the possibility of further study from different angles, calling policy-makers' attention to the problems of healthcare services in the community healthcare centers in rural Bangladesh.

\section{Research Methodology and Data Collection Techniques}

A qualitative study has been conducted in order to meet the objectives of this study. Qualitative research helps to explore and understand the profound experiences, attitudes, perceptions, and interactions of the respondents in real-life situations (Islam, 2011). Exploratory-Qualitative research design has been employed in this study to enable an in-depth analysis regarding the answers to research questions. A field study was conducted to collect the necessary data regarding the study objectives. Field data were collected from three community clinics located in three different sub-districts (Upazila) of Sylhet district in Bangladesh. Twenty-one (21) respondents, consisting of local beneficiaries (community people), healthcare providers at the community clinics, government officials, and locally elected representatives, have been selected for this study. The respondents have been selected purposively from three community clinics located in rural areas of the Sylhet Division, Bangladesh, to cross-check the information of the local beneficiaries. The researcher developed an open-ended interview guideline to collect primary data from the respondents through in-depth interviews, as the individual interview method is beneficial for intensive investigation (Creswell \& Creswell, 2017).

Furthermore, individual in-depth interviews are more useful for getting actual information from different types of respondents, and the researcher has the opportunity to clarify and better understand the views through direct contact with the respondents (Islam, 2011). Besides, two Focus Group Discussions (FGDs) have been conducted with the members of the community group (CG) and community support group (CSG) for two different community clinics.

The community group is formed as the advisory body and fundraising authority for effective management of the community clinics. Each community clinic has one community group consisting of 15 members, as well as three community support groups comprised of 17 members each. The researcher analyzed the qualitative data by applying a thematic analysis approach. The themes were identified in line with the relevant codes of all transcripts through repeated readings. Direct quotes and conversations with the respondents have been presented here to support the variables. For ease 
and to avoid repetitive duplication of the references, the endnote reference manager was used in this study, with all references employed in this study managed using the endnote library. Documents from government agencies and archives were also reviewed to provide institutional data that support this study and present its findings as a product of qualitative investigation. In this study, the researcher has used some local dialects directly collected from the respondents to make the respondents meaning clear to all. Furthermore, some cultural and traditional medicines and medical terminology, as well as local terms related to health and treatment has been used here in an effort to avoid changing the sentiments of the respondents. The researcher considered each theme as an influential factor in finding the answers to the research questions.

\section{Review of Relevant Literature}

Some books and articles related to this study have been inspected or reviewed to identify the knowledge gap and understand the concept clearly with the building of theoretical knowledge.

\section{Access to the community clinics: does it ensure equal opportunity?}

Access to health care includes both potential and realized access. More than half of uninsured people have the socioeconomic status of immigrants, with lower access to regular health care than insurance holders (Douangmala, Hayden, Young, Rho, \& Schnepper, 2012). Most migrants and refugees, therefore, receive healthcare services in community clinics. A study conducted in the USA by (O'Malley \& Mandetblatt (2003) found that 12.024 respondents who were living $200 \%$ below the poverty threshold were using community clinics. Other community clinic users include the less educated, ethnic minorities, those in poorer health, and the uninsured, which face time, transportation, and treatment cost barriers compared to those who can visit private doctors (O’Malley \& Mandetblatt, 2003). Caste and race are the two major hindrances to equal access to rural healthcare facilities. In the USA, by 1999, 438 community clinics were built, 212 were upgraded, and 2,298 were considered to be well equipped, while clinics for black townships increased from 8 in 1987 to just 19 in 1997 (Foster, 2005). In most of the community clinics, the white patients got preferential treatment; they were called first and treated courteously by the staff, which was not the case for black patients (Foster, 2005). Socio-cultural, religious and political factors influence the health care provisions in Nigeria (Adeyemo, 2005). However, in India, the appreciative efforts of the community clinics decreased the hypertension of the aged people significantly, and the attributes of caste and religion did not have any impact on the result (Premkumar, Pothen, Rima, \& Arole, 2016). In the community clinic, the behavior of the staff and quality of services depends on the socio-economic background of the patients, and nepotism is a common 
factor in how community clinics provide services (Mashego \& Peltzer, 2005). Community participation in development projects in rural areas of Zimbabwe was not only lower but also top-down, which creates negative perceptions because of the involvement of external agents who view the local people as passive recipients of the services (Jacob \& Bernard, 2013). Furthermore, the power dynamics and preferential treatment for special groups impede the active participation of the community (Jacob \& Bernard, 2013). The socioeconomic indicators of health are also important factors to determine the social position and different material circumstances (Wilkinson, 1997).

\section{Service delivery of $\mathrm{CC}$ : how far does it meet the local demands?}

In Australia, community health care providers are competent enough, and they are reoriented with skilled training and proactively keep up with future planned changes in their healthcare system (Day, Levett-Jones, \& Taylor, 2014). The health providers also provide training to teachers because health is a multi-dimensional concept, viewed not only in terms of physical and psychological well-being but also the social and cultural well-being of the whole community (Munns, Forde, Krouzecky, \& Shields, 2015). Community clinics are reducing the rates of premature death, rheumatic fever, and infant mortality (O’Malley \& Forrest, 1996).

Furthermore, community health workers are very effective in counseling to the mothers of their sick children at home, resulting in a $40 \%$ reduction in mortality for children less than five years of age (Haines et al., 2007). In the USA, community health centers have a significant role in reducing diabetes and asthma through regular check-ups of urine, blood, and diet (Silver et al., 2011). The critical challenges in the management of local primary health care services include lack of skilled workforce, lack of finance, inadequate transportation and political instability as well (Adeyemo et al., 2005). In African countries, most of the patients, along with their family members, have continued to seek care through other sources due to the poor quality of health services provided by the community clinics (Okwaro et al., 2015). Moreover, cultural diversification and local class relations negatively affect healthcare provision strategies and draw public criticism due to corruption, low pay for the staff, and poor working conditions in the community clinics themselves (Foster, 2005). Although the mental healthcare service provided by the community clinics is typically effective, the problem of stress is overlooked in community clinics due to a shortage of time, lack of skilled workforce, and the reluctance of the patients (Goodrick, Kneuper, \& Steinbauer, 2005). 


\section{Systematic problems of decentralized health Care}

While the prime objective of establishing community clinics is to bring health care services to the doorsteps of the community along with their active intervention, the communities are not part of the budgeting and planning processes of the community clinics, as they are considered the active users of the clinics (Chirenje, Giliba, \& Musamba, 2013). In rural community-based healthcare programs, the committees are formed only in name, but their functions are often limited to serving as a liaison between the community and healthcare workers (Adato, Hoddinott, \& Haddad, 2005). In Nigeria, limited fund disbursement to local authorities from the central government creates an obstacle to providing quality primary healthcare services in local regions (Boris, 2015). Besides, ambiguous decentralization and sectoral laws create insufficient clarity in many areas regarding specific services; sometimes, the central authority interferes in the delivery of healthcare services at the local level (Martinez-Vazquez, 2011). Vertical fiscal imbalances, soft budget constraints, and decentralization of corruption at the local level are the main challenges of decentralization in any country (Martinez-Vazquez, 2011).

Furthermore, mismanagement of resources, fewer centralized agencies to enforce honesty, lack of monitoring tools and systematic fiscal decentralization are the significant obstacles faced by local institutions in providing services at the local level (Fjeldstad, 2004). Central fund disbursement down through different tiers of government, direct interaction with the public at the core point of service delivery, and power patronage networks are the factors serving to broaden the room for corruption at the local level (Transparency International, 2009). Besides, decentralization creates an imbalance between upward and down accountability and turns the performance of the local level administration into weak due to lack of clear functional jurisdiction and adequate monitoring tools which traverse to enlarge the scope of the despotism of the employees (Scott, 2009).

\section{Community Clinic in Bangladesh as a Decentralized Health Care System}

During 1996-2001, the Awami League government of Bangladesh planned to establish community clinics at the grassroots level to bring primary healthcare services to the common people all over Bangladesh. In this context, 10.723 clinics were established during 1998-2001 (MOHFW, 2016). In Bangladesh, the healthcare provisions are dispersed into different levels, from the central to the local (Ahmed et al., 2005). The health care administration is operating in Bangladesh through three leading rungs, as shown in the figure: 


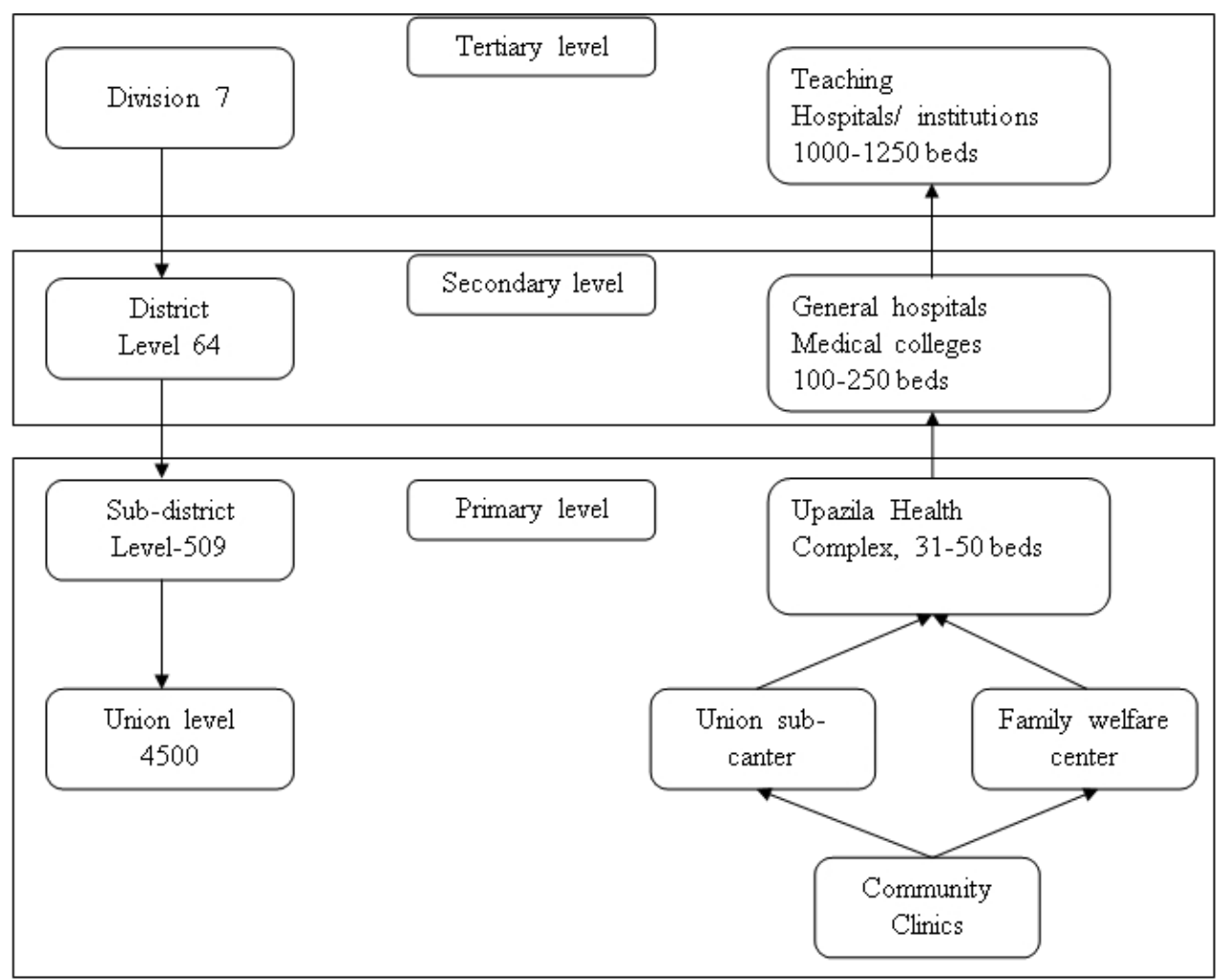

Figure 1: Level of decentralized healthcare provision in Bangladesh Source: (Kouam et al., 2014).

At the tertiary level of Bangladesh, there are seven divisions, and for every division, there is a government hospital with a good number of beds for the patients. The secondary level of the health care system in Bangladesh is scattered over sixty-four districts, having general hospitals and medical colleges (Kouam et al., 2014). In line with the policy strategy of equal and quality health care for all, the government has endorsed a primary health care approach with a particular focus on the rural population and the poor (Hasan, 2012).

\section{Organization and Management of Health Care System in Bangladesh}

In Bangladesh, the health care management system is very complex and hierarchical in nature, as shown in Figure 2. Ministry of Health and Family Welfare (MOHFW) and Ministry of Local Government, Rural Development, and Cooperatives (MOLGRDC) are the responsible ministries in Bangladesh to provide health care services both in rural and urban areas. 


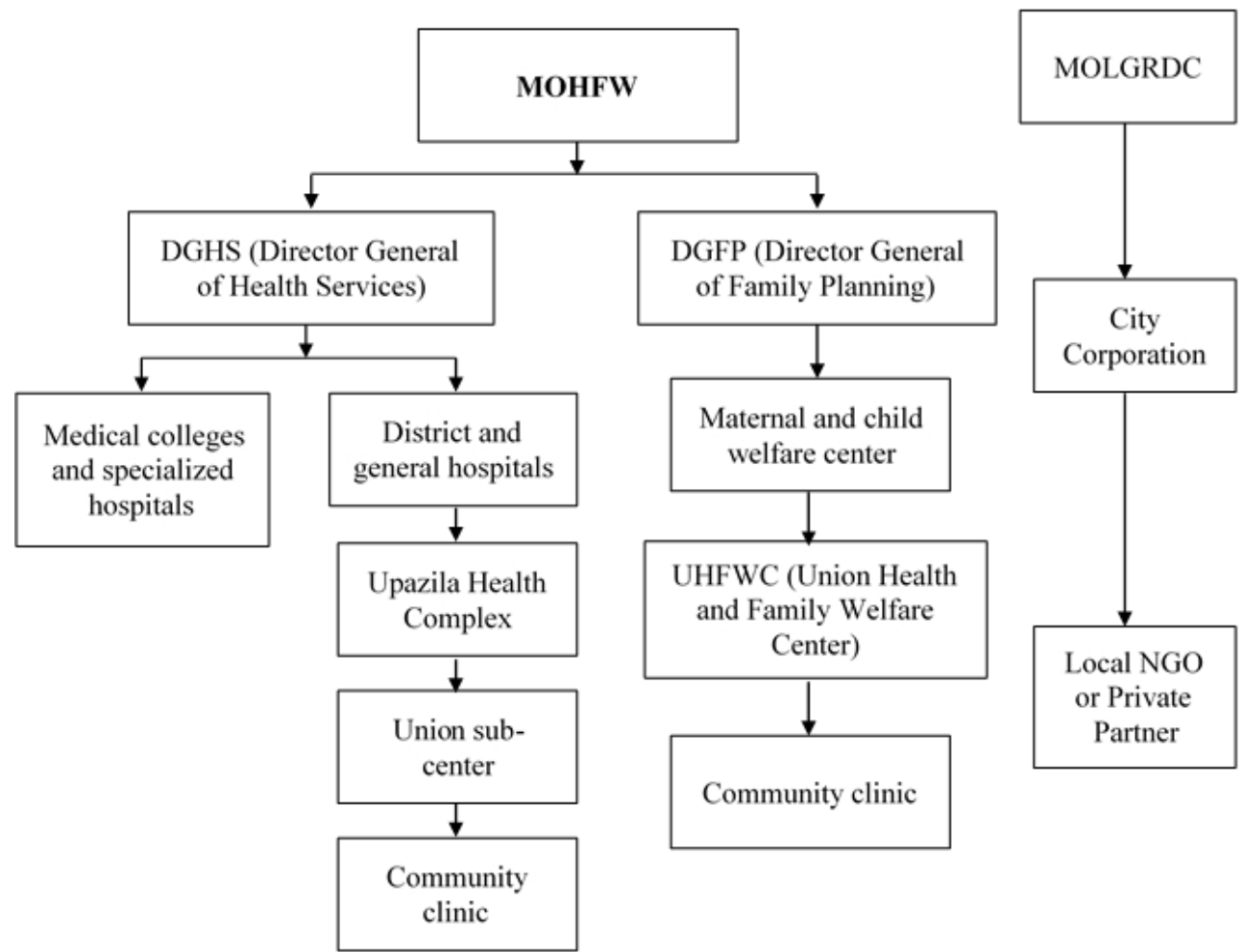

Figure 2: Organization and Management of Healthcare Systems of Bangladesh Source: (Ahmed et al., 2015).

As shown in the above figure, the health care structure in Bangladesh is arranged in a pyramidal shape where the legal power and ultimate authority lies at the hand of ministry (Ahmed et al., 2015).The coordination with central authorities is very bureaucratic; it also brings jealousies and jurisdictional disputes (Pradeep, 2011).

Mainly the DGHS and DGFP control the tertiary, secondary, and primary levels of health care services through concerned agencies and institutions. Hence, City Corporation plays a vital role in coordinating and manage the health care institutions of urban areas with collaborative negotiation to the development partners and NGOs under the directions of MOLGRDC (Ahmed et al., 2015).

\section{Findings and Discussion of the Study}

\section{Challenges of Access to the Health Care System of Community Clinics Socio-economic factors}

In rural Bangladesh, the socio-cultural system is very conservative and traditional. Most of the rural people are poor and illiterate, so they are still often oblivious to their health. Some local rural people believe in the charismatic power of the "Kabiraz" (local traditional quack or spiritual 
treatment provider) instead of modern medicine. They are devoted to religion and indiscreetly believe in traditional superstitions that prohibit them from getting treatment at the community clinic. The study findings revealed that some rural unconscious people never support family planning programs, either for males or females, and feel better going to the "Mazar" (grave or tomb of prophet-like person) to obtain a cure through spiritual prayer. Patients in more primitive villages are inclined to seek treatment from informal health care providers than the more advanced villages (Hamid, Sadique, Ahmed, \& Molla, 2005). During FGD, a member of the community group said:

"Some religious leaders in the society give "fatwa" (religious theory) for the local people that the family planning program is forbidden in Islam. They also said that God would feed the newborn who has created him/her."

The rural villagers do not have equal access to healthcare facilities provided by the community clinic, irrespective of caste, race, and socioeconomic background. The socio-economic backgrounds of the patients determine the quality of services and behavior of the doctors toward them in the community clinics (Mashego \& Peltzer, 2005). Nepotism is a common feature of community clinics in terms of providing services. However, the study findings of this study differ from those of the systematic review of Premkumar as he wrote that the people of rural areas of central India are getting equal treatment from the local community clinic irrespective of sex, caste, race, and religion (Premkumar et al., 2016). When the rich, educated, and powerful patients come to receive treatment, they are treated differently than other patients. They get a full course of medicine, and also antibiotics and contraceptives from the CHCP (Community Healthcare Provider) for their relatives and family members. The day labor and migrant patients claimed that the healthcare providers are reluctant to provide them medicine, as they do not have resident cards for that particular region. During FGD, a community group member stated:

"Some poor patients claim that they do not get medicine as well as good behavior from the doctor and staff of the community clinic. The poor patients get less priority here. They have to wait for a long time to take medicine, and they rarely get antibiotics from the community clinic; there are some chairs where the poor and low-level patients cannot sit".

The poor and marginalized people are the primary beneficiaries of the community clinic. Most of them are illiterate and live hand-to-mouth, so they cannot imagine visiting the government or private hospitals. However, rich people sometimes visit a community clinic and get special treatment. In line with this study finding, Jana \& Harata wrote that the rural poor visit the community clinics for treatment because they are provided medicine and 
treatment free of cost (Jana \& Harata, 2016). Besides, migrant poor, less educated, and ethnic minorities are the prime seekers of CC because of face time, transportation, and cost of treatment (Douangmala et al., 2012; O'Malley $\&$ Mandelblatt, 2003). The quality of services and equal access to community clinics are mostly affected by both demand and supply-side factors (Hamid et al., 2005). The healthcare providers' acceptability and accessibility to the rural people are often a challenging matter. The healthcare providers claimed that they did not operate the family planning program and did not go to the villagers' homes because of the threats and criticisms from the male members. They also mentioned that due to lack of education and awareness, sometimes they are not allowed to talk with their wives or other female family members. A healthcare provider stated:

"When we push injections to the children, they often cry, then their mothers and other family members attack us orally. After pushing some injections, they see some abscess-like symptoms on the skin; then, we have to face threats, criticism, and mockery from the rural people."

\section{Political factors}

A lack of political commitment and policy continuity of the government with regime change hampers the service delivery system of the community clinics (Sultana \& Tania, 2015). Upon this topic, the respondents in my study indicated that political power practice and polarization are the two dominant challenges to access to community healthcare services for the rural people. The Awami League government has established community clinics at the village level, so the opposition party members rarely visit the community clinic for treatment. However, when the opposition political party attained state power, it closed the community clinics throughout the country for a long time. Now CCs are functioning with its full swing in Bangladesh, as Awami League government holds the state power again. The local people think that the government is taking over the rural power structure through these community clinics. The local politicians and power holders never maintain the regulations of the community clinic, and they get all types of facilities and medicines from the health providers. In contrast, the poor and vulnerable groups never get quality medication or better treatment from them, as Jacob\& Bernard wrote, the rural power structure influences the service delivery systems of the community clinics, where some special groups get preferential treatment, and for this, the objectives of the community clinics turn into another (Jacob \& Bernard, 2013). The power holders get warm greetings in the community clinic when receiving treatment, and they roughly enter into the clinic. They have linkages with upper-level policy-makers and administrators so that they can claim more attention from healthcare providers. Furthermore, a CHCP said: 
"The local political leaders have some followers at the local level that can do physical or psychological harassment to anybody following the order of the leaders. So, the general patients and providers do not make any contention with them."

During the interview, a male patient noted:

"[... I I was able to enter into the room of CHCP after a long serial for taking some medicine for my stomach pain. I was expressing my problem to the doctor, but the doctor ordered me to leave and come back later, as a local political leader entered his room without maintaining any serial. More than half an hour has gone, and I am still waiting for the doctor. We are poor, so we have to wait and take medicine."

Political manipulation and nepotism undermine the quality of healthcare services of the community clinics in rural Bangladesh (Islam \& Biswas, 2014). Most local people know well about the unfair recruitment process of health care providers and staff of the community clinic in Bangladesh. The CHCP, FWA (Family Welfare Assistant), and HA (Health Assistant) have been recruited, providing bribe to the upper-level officials.

During FGD, a female member of the community support group stated:

"Merit does not matter now in Bangladesh. All types of jobs are now available in Bangladesh based on nepotism and bribery. I became the second in the written and oral exam for the post of CHCP in this community clinic. However, I had no ability to provide money to buy this post. As a poor student, I got out of the job, and now I am still an unemployed person. NB. The CHCP of this community clinic is the niece of a member of parliament."

The rural local political person never follows the rules and enters the doctor's room without any permission. This hampers the treatment, and the clinic cannot protect the privacy of the patients.

\section{Does gender matter?}

The social family structure of Bangladesh is male-dominated. The female members may be educated, but the decisions are made by the husband or male leader of the family. Most of the families in rural Bangladesh strictly maintain "Purdah" (Hijab or veil) for their female members, and the male leader of the household never permits them to visit male doctors. The sociocultural system treats women only as workers in the household. Even in emergencies, women and girls do not share any information outside the family about their private diseases. Also, the rural family structure in Bangladesh is very conservative and traditional. Women are dominated and discriminated against in every sphere of life. Most of them remain in the house and do all the work for the family (Deeb-Sossa, 2007). Furthermore, in the case of 
treatment, the younger family members, especially the women, have to obey the older members of the family. As Nana et al., observed in his study on Ghana, most of the women in Ghana are influenced by the elder members of the society in seeking treatment (Ackatia-Armah et al., 2016). One female patient explained:

"We get different treatment from the family and husband. When male members of our family get sick, they visit the clinic or hospitals without any permission from the family leader. However, we usually cannot imagine it, even in an emergency situation we have to stay at home. My cousin's husband was an illiterate and conservative person. At the time of my cousin's first baby delivery, a complication arose, but they did not take her to the hospital, and she finally died, ah."

Traditional socio-cultural and structural factors prevent women from accessing healthcare facilities from birth through adolescence to old age (van der Hoeven, Kruger, \& Greeff, 2012).

Most of the rural patients would not talk about their private diseases to a healthcare provider of the opposite sex. Most of them stated that every community clinic should have two $\mathrm{CHCP}$, one male, and one female. One male patient reported:

"I have been suffering from itching in my testicle for more than three months. Several times I have come to this clinic for different reasons, but I could not mention the name of the disease to the female doctor. At last, I myself came along with my wife and sent her to the CHCP for taking medicine."

Bangladesh, the unequal distribution of power relationships between men and women in all aspects of life tends women to be subordinated, discriminated, and violated at the hand of the state, society, community, and family (Islam, 2019). The female patients face a hefty number of problems from family and the state. A female patient noted:

"In the immunization day when we the young unmarried girls go to the community clinic to get an injection from the FWA or HA, some young boys tease us on the way, saying pregnant, pregnant. For this reason, many young girls stay away from the immunization program."

\section{Geographic location and time}

In most areas, the beneficiaries and officials of community clinics are not satisfied with the location of the community clinic. They stated that since the government established the community clinic on land donated by somebody, it is not held in the planned way. In addition to that, most of the community clinics are located at the corner of the ward or union; hence, the local patients have to walk for a long distance to receive treatment from the community clinic. Sometimes it is a bit difficult for pregnant women, older 
people, and children to visit the community clinic. Almost 50 patients visit the community clinic every day, and the $\mathrm{CHCP}$ alone provides primary healthcare services for a large number of local patients, which is challenging to maintain. For this, the patients have to manage a long serial for receiving treatment from the community clinic. This is illustrated by the following statement from a local patient who had to wait for a long time. One female patient noted:

"We are poor; we have to live on day labor. Since morning we have been waiting to take medicine. We are sick now, so we are taking rest under the tree. There is no waiting room here for the patients, so we have to wait outside the clinic even in the sun and rain. We have no ability to visit private clinics or hospitals, so we are bound to accept all the rules and regulations. We wait for a long time, but we did not get the necessary medicine. The doctor provides normal medicine for three days at a time, which does not cure the disease, so we have to come here again and miss our daily work."

Furthermore, the transportation system is very backward, so most patients have to walk to the community clinics on foot. Although there should be at least three community clinics for providing services to a small number of people in each union, it is rare to see two clinics in any union. In most cases, there is only one community clinic for each union, so it makes the patients' access more difficult due to long distances and over the profusion of patients. However, this study finding is contradictory with the analysis of Normand et al., who stated that most of the community clinics are located in perfect places and in organized structures, where the patients can visit the doctors within only 30 minutes walking distance from their homes (Normand, Iftekar, \& Rahman, 2002).

\section{Quality and Quantity of Services and Local Demands Types of services provided at the $\mathrm{CC}$}

The majority of respondents agreed that they mainly get three types of treatment and assistance from community clinics, like primary health care, referral opportunity to the government hospitals for complex and critical diseases, as well as maternal and child health care. The CHCP provides treatment for fever, cold, cough, headache, pain, burns, anemia, diabetes, blood pressure, diarrhea, eye conjunctivitis, ear diseases, asthma, gastric problems, and small injuries in the community clinic. The local patients receive prenatal and postnatal services for both mothers and children. Most of the villagers get contraceptives for birth control and necessary counseling for family planning from the FWA and HA at the community clinic. The immunization program of the community clinic is very useful for rural mothers and children; every Thursday, the clinic arranged an immunization program for women and young girls from 15-49 years of age who are eligible 
to be pregnant. Pregnant women get special care from the community clinic to preserve their own lives and those of their coming children. Furthermore, rural villagers receive instruction regarding balanced diets for children, pregnant mothers, and new mothers.

Diabetes and blood pressure measurement is also taken at the community clinic. Rural pregnant mothers can have an opportunity for a normal delivery at the community clinic if held in the opening time of the clinic.

A CHCP stated:

"We provide thirty-two types of treatment in the community clinic. Besides primary health care, this community clinic is renowned for providing treatment for pregnant women and postnatal services both for mothers and children. We also provide and disseminate health education and knowledge to the local people about how to prepare $O R S$ in the time of dehydration, what to do in the rime of serious fever and blood pressure, how to feed the children."

Building health awareness among rural people is also a significant concern of the community clinic. The community support group makes villagers aware of the available services and inspires them to visit the community clinic for treatment.

\section{Quality and quantity of services of the CC}

The community clinics provide treatment only for common types of diseases. On this point, I found that all of the patients get low-quality care and only a small amount of medicine from the healthcare providers at the community clinic. Despite having the infrastructure, community clinics cannot provide better health care services according to the needs and demands of the community (Ahmed, Bose, \& Persson, 2007).

A CHCP said that "each community clinic gets 3,000 pieces of ordinary tablets and 500 pieces of antibiotics from the UHC (Upazila health complex) to provide health care to the community people for three months."

The patients at the community clinic complained that they have no bargaining power in obtaining medicine from the $\mathrm{CC}$. The underprivileged patients get medicine only for three days at a time, which does not constitute a full course of medicine for the treatment, so the medicine does not cure the disease. Community clinics in Bangladesh provide thirty-two types of treatment for rural patients, and most of these treatments are very normal. There is an inconsistency between the number of treatments mentioned in the charts of $\mathrm{CC}$ and reality. In most cases, the doctor and the staff of the clinic refer the patients to the city hospitals, as there is no proper treatment capacity at the clinic itself. Mental disorders, disability, and stress management appear on the prospectus as treatments available at the community clinics; however, 
none of those diseases are managed here because of the shortage of workforce and time. The findings of my study are consistent with the earlier findings of (Goodrick et al., 2005). The service users of the CCs in Bangladesh are not satisfied with the quality and quantity of health care services.

The low-quality medicine, panacea, shortages of medicine, instruments. MBBS doctors, technology, and infrastructure are the preeminent concerns of the local patients regarding the quality of services available at the $\mathrm{CC}$ in Bangladesh, as Okwaro et al. expressed his research findings in the context of African countries (Okwaro et al., 2015). During the interview, one male patient stated:

"We request the doctor to give us a full course of medicine, but s/he does not provide it, saying that it is against the rules. In most cases, the doctor does not diagnose the diseases accurately; he gives us cheap medicine and prescribes the quality medicine from an outside pharmacy. We are poor; how we will buy that costly medication?"

The study findings revealed that in each community clinic, there is only one CHCP to provide health care to the masses, and they have to manage a large number of patients alone as the only permanent employees in the community clinic. The respondents also stated that there are two other officers in the community clinic to help the CHCP. The CHCP and two other officials are the domiciliary staff, and the CHCPs received only three months' training in public health after passing their secondary or higher secondary school certificate. Therefore, $\mathrm{CHCP}$ cannot offer all types of treatment for all diseases. One CHCP said:

"I am not an expert in all diseases: I have some background in primary health care. During my training period, I have learned some practical knowledge of public health. Only three months' training is not enough to provide quality health services for the local patients. An MBBS doctor cannot learn by heart all matters of health during their six-year study or internee period, so how would I be able to provide all treatments?

Furthermore, the FWA and HA are not always available in the clinic except on immunization days. They have to visit the field to register the names of pregnant women and newborn babies who are required to get immunizations. Most of the respondents stated that there is no laboratory in the community clinic to diagnose the diseases, the environment of the clinic is dirty and shabby, and the delivery room is often closed and unused. However, there were some varied perceptions among the respondents about the quality and quantity of services of the community clinic. In Bangladesh, the rural healthcare system significantly reduce maternal and child mortality rate. The FWA and HA are well trained for neonatal and postnatal care. Every week they arrange immunizations for women 15-49 years of age and children of 0- 
5 years in the community clinic. Due to the efforts of the community clinics, the maternal and child mortality rate has been reduced dramatically (Ahmed et al., 2015).

Also, O'Malley and Forrest in line with this study finding stated that CC provides healthcare services to rural beneficiaries and reduces the premature death and infant mortality rate (O'Malley \& Forrest, 1996). The Family Welfare Assistant and Health Assistant also arrange counseling for pregnant women and newly married couples before giving birth about safe motherhood and the usefulness of contraceptives. They refer the female patients with gynecological complications to the hospitals for better treatment and motivate them to do the pathological test for making truth (Munns et al., 2015). Some poor respondents explained their views positively and mentioned that before the establishment of the community clinic, the rural poor suffered a lot, but now they get medicine and treatment here free of cost. One male patient noted:

"My elder daughter was suffering from stomach pain; I took her to the clinic, and the doctor gave her antacid tablets for gastric trouble. Now my daughter is all right. In this way, the villagers are getting many healthcare services from this clinic. The normal delivery of pregnant women is also done here without any cost. I think that whatever we are getting from here, is not so bad."

The respondents of this study agreed that the health and immunization program for mothers and children is satisfactory. Community clinic is working hard along with other governmental and non- governmental organizations to make polio-free Bangladesh.

\section{Organization and management of service delivery}

The study findings regarding this theme are very specific and clear. The FWA and HA have been recruited in this clinic as the helping hands of the CHCP. The FWA has been recruited under the Director-General of Family Planning (DGFP), and the HA has been recruited under the Director-General of Health Services (DGHS).

They are experts in immunization and family planning programs. So, they cannot stay and give full-time support to the CHCP at the community clinics, as they have to be responsible for their own fields. The CHCF is the only person responsible for providing primary health services in the community clinic, as stated by a CHCP. The opening period of the community clinic for providing services is very short; only four hours for delivering health services and two hours for registration of the names of medicines are provided to the patients. 
Most of the respondents replied that there is no timetable for opening the community clinic, although they know that the clinic should be open from 9 AM to 3 PM. Sometimes they find that the clinic is closed for no reason. During FGD, one participant stated:

"Every day I observe, the CHCP comes to the community clinic after 11 AM and closes it before 2 PM. I have seen her do this regularly, as she has to come through the yard of my home. I thought that it is the timetable; however, is nobody concerned about this illegal conduct?" Each community clinic has the capacity to provide services for six thousand people, and the medicine is offered to them as per the rules. However, in most unions, there is only one community clinic instead of three due to the lack of donated land. The healthcare providers have to provide treatment for more than twenty thousand patients in this union with this amount of medicine. A healthcare provider stated:

"In this Union Parishad, there is one community clinic for more than 18,000 people, but I get medicine for only six thousand people from the UHC. How will I manage this large number of patients with so little medicine? The Upazila health officer would never give me more medicine, and I cannot close the clinic due to the lack of medicine. So, I provide only a small amount of medicine for every patient."

\section{Decentralization and the Service Delivery System of Community Clinic}

Through the decentralized health care system, the local people are getting services easily from the community clinics and other primary level health care centers. Before establishing these clinics, rural people had to suffer a lot. The city is far away from the villages, and the transportation system requires high cost, so most villagers visited traditional providers instead of doctors. Decentralization creates the opportunity of receiving primary health care services very close to the community. They not only receive free treatment and medicine from the CC but also consultancy. As Panday stated that decentralization is a process of improving the quality and accessibility of local services and thus promoting local level development (Panday, 2011). However, there are some problems with decentralization which affect the local level development negatively.

\section{Community participation: form or reality?}

Systematic problems with the decentralization process hamper the service delivery system of the community clinic in rural Bangladesh. The $\mathrm{CHCP}$, elected representatives, and Upazila health officer (UHO) in the study said that the leading problem with the decentralized health care delivery system of the community clinic is the lack of community involvement. 
The formation and implication of community group and community support groups in planning, implementing, and decision-making regarding the management of the CC is not free of controversy; as Mansuri and Rao stated that poor people of the rural community have limited access to be benefitted from local development programs, as most of the decisions depend on the wish of elite class (Mansuri \& Rao, 2013). The ideal and reality about the power and functions of the CG and CSG do not match. Community involvement is a voluntary job, and communities look after their clinics. They have to provide $\$ 1.2$ each month to the welfare fund of the clinic. The CG and CSG do not receive any incentives or wages from the government or clinic. Every month the $\mathrm{CHCP}$ arranges a general meeting at the clinic premises with community group members to discuss problems and prospects of the service delivery system, but very few are present. During the interview, a CHCP stated:

"I call the community group members with my mobile phone to attend the meeting at the community clinic. I have no extra budget or person to invite them physically. However, they asked me first whether there is any TA/DA or remuneration for them. When they are informed that it is a general meeting to discuss various issues of the CC, most of them never attend the meeting, but if there is some gift, they attend the meeting and present at the CC premises earlier than the fixed time."

In the decentralized local development projects, community participation remains only in name, but not in reality. Community participation in Bangladesh is a voluminous termination in any local-level projects that remains a myth (Mohammad, 2010).

\section{Local-level autonomy: A controversial issue}

With respect to this theme, the study findings reveal that decentralization is in name only and not in practice. The decentralized health care administration is fully controlled by the MOHFW, and the field level administration is solely responsible for carrying out the directions of the central government for implementing the local development programs. The concerned ministry grips the responsibilities of financing, staffing, budgeting, maintenance and infrastructural development for service delivery at the local level. The appointment, transfer, posting, and salary structure of the officials of local health care institutions are determined by the ministry (Ahmed et al., 2015). In the name of decentralization, the central government is diffusing the power and authority of the local level institutions (Boris, 2015).

Through this decentralized health care system, the central government appoints all of its followers in different positions in local institutions, trying to perpetuate their power at the local level.

The land donor, chairman, and members of the community group and community support groups are usually affiliated with the ruling party. 
However, local elected representatives of the opposition party do not get the post of chairman of the community clinic. There is no clear picture of the rules of business of the community clinics regarding the scope and nature of the power and functions of the local people. The CG and CSG members stated that they do not know the selection criteria for the members of these two groups, but they confessed that most of the members of the CG and CSG are supporters of the ruling party. In response to the question of selection criteria for the members of $\mathrm{CG}$ and $\mathrm{CSG}$, most of the healthcare providers and key informants said that the CHCP is asked to select the names of the members from different groups in society and send them to the Upazila health office. Then the UHO authorizes the names and sends the list to the civil surgeon office for their information. The elected representatives and community members said that they have responsibilities but no power. Systematic weakness of the decentralization of primary health care in rural Bangladesh creates problems regarding accountability, coordination, and links between different actors and functions of delegation, finance, performance, information, and enforcement (Ahmad et al., 2007). Sometimes local authorities receive information about illegal activities of the $\mathrm{CC}$, and some patients complain about dereliction on the side of the staff and doctors of the CC. However, the local elected representatives and community members have no legal power to take any action. In Bangladesh, decentralization efforts have been implemented through reform initiatives, only to strengthen the central government influence in that particular region During FGD, a member of CSG noted:

"We have informed the UHO about the illegal activities of the healthcare providers several times, but nothing happened as it is a bureaucratic system."

\section{Coordination and responsibility: misaligned or specified?}

Coordination is essential to synchronize the functions of different levels and to solve the problems of an institution or organization. As a system, the community clinic constitutes several activities and elements to achieve common goals. From local people to the ministry level, officials are related to the service delivery and management system of the community clinic.

However, their responsibilities are misaligned and unclear. Through decentralization, ambiguous power and functions are transferred to the local authority, which never emulates local aspirations (Islam \& Biswas, 2014). There is no coordination among the local government officials, local representatives, and higher-level health officials to foster the service delivery system in rural areas. One government official said:

"[...] lack of coordination among the community people hampers service delivery system of the community clinic." 
Different categories of people from diverse levels i.e. community people, local elected representatives, UHO, UHFP, District civil surgeon, DGHS, and DGFP, are functional in the service delivery system at the rural local community clinics.

"It is very convoluted to coordinate among all these departments. There are some misaligned responsibilities both at the local and central levels. So, the main problem of decentralization is proper coordination and forming a polycentric system at the individual level. So, sometimes a lack of coordination hampers the service delivery system of the CC," as stated by a local government official.

A decentralized health care system does not clarify the functional jurisdictions among the local officials and representatives. These overlapping or ambiguous functions create conflict between these two groups. Ministry of health and family welfare (MOHFW), Director General of health service (DGHS), and Director General of family planning (DGFP) are the upper-level decision- making offices, and local health providers cannot communicate with them due to considerations of status and hierarchy (Ahmed et al., 2015).

\section{Dynamics of accountability and transparency}

The officials of the community clinic are not accountable for or transparent in their performance, and there is a controversy between the statements of healthcare providers and the monitoring authority of the clinic. Healthcare providers stated that although there is a rule that the clinic is visited by the district civil surgeon once a month and by the Upazila health officer and medical officer twice a month, they, in fact, rarely visit the $\mathrm{CC}$. There is no central agency to ensure the accountability and transparency of the decentralized local level institution (Aminuzzaman, 2010). The healthcare providers and staff of the community clinics claimed that in the decentralized health care delivery system, the medical officer is responsible for visiting the local patients in the community clinic, but for the last two months, they have not come to the clinic.

The community people do not know the actual amount of medicine that the CHCP gets from the health office. Most healthcare providers register the names of drugs provided to the patients, but this study found that some healthcare providers entered the names of some medicines that were not given to the patients. One CHCP noted:

"The civil surgeon never takes account of medicine from me; it is only a formality."

There is a provision for free treatment at the community clinic. But the majority of the patients contributing to this study stated that healthcare providers take money from the patients for pathological tests; without this money, they do not do the test. A male patient stated: 
"I am a patient with high blood pressure. I have come to the clinic to measure my blood pressure today, but the doctor demands 50 taka from me for this test. When I refused to give her money, she said to me that the color of my eyes is ok, so you need not check your pressure. There is no one to see this corruption."

The present perceived corruption rate in the health sector of Bangladesh is higher (24\%) than for Peru or Kazakhstan, where the perceived corruption rate is 20 and 9 percent, respectively (Lewis, 2006). The monitoring authority of the community clinic stated that because of this decentralization, the primary health sector had encountered new problems with accountability. A local government health officer said:

"In the last civil service exam, the government-appointed about 15,000 $M B B S$ doctors to work in the rural areas in Bangladesh. The newly appointed doctors are very busy with developing their career and neglect their primary duties. They apply for transfer to the city hospitals or obtain leave for higher studies. Hence, the government cannot fulfill the demands of local communities for quality services from MBBS doctors."

MBBS doctors do not stay in rural areas in Bangladesh (Ashaduzzaman et al., 2005). They transfer to urban hospitals to get the opportunity of good schools for their children, extra income from visiting patients in clinics, better communication, and transportation, etc. The ambiguous decentralization process enlarges their scope of absenteeism. A health care provider said:

"FWA and HA remain absent most dais of the week except immunization day. If the monitoring authority visits the clinic in the meantime, I call them by mobile, and they ask me to put their name in the attendance book to convince the authorities that they are in the field."

Nobody is responsible for ensuring the better service delivery system of the community clinic; everybody wants power but avoids responsibility.

\section{Funding procedures and health care services}

There is no welfare budget for the maintenance costs of the community clinic, like electric bills, floor cleaners, hand wash, refreshments, and snacks. The CHCP can withdraw their salary after six months. The community clinic gets a small amount of financing from the central government to buy medicine and vaccines for the community people. The salaries of the healthcare providers come through the Upazila health officer after five or six months, due to the complex system of fund release. The financial layout process from the central government is small and delayed, and funds disbursement down 
through different levels leads to corruption (Boris, 2015). A local-level health official said:

"The community clinic is running as a project funded by the UNICEF and USAID. Then the Bangladesh government disburses the fund to the CC through the director-general of health and family planning. The concerned department sends the budget to the district civil surgeon office, and then the civil surgeon sends it to UHO, and from the UHO, the CHCPs receive their salaries."

He also said that there are many controversies about the medicine of the community clinic, but did not go into personal details, requesting that I do not ask him anything about it or he would leave the room. There are no incentives for the healthcare providers besides salary, which encourages them to become involved in illegal activities. One local level healthcare provider stated:

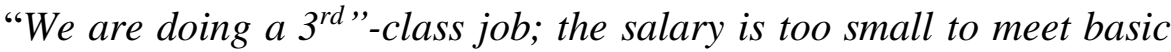
daily needs. I do not sell the medicine, contraceptives, and birth control pills and injections to the local quack or private pharmacy, but I know some healthcare providers do this illegal job because of their low and irregular salary."

Besides, primary health care in Bangladesh is elite-biased, urbanfocused, and curative care-oriented (Kalam \& Parvin, 2015). The majority of the service receivers are the poor or middle class, but they do not receive equal treatment from the healthcare providers. As Mosse wrote, the nature and benefits of participation in the local development projects are based on local power relations (Cooke \& Kothari, 2001).

\section{Conclusion with Policy Recommendations}

Community clinics have been established in every union of rural Bangladesh to ensure easy access to the local community to primary health care, particularly the poor and disadvantaged. However, this study finding reveals that most of the community clinics are located in boggy ground and are put on the side of the fixed region subject to bumping. The community people do not have equal participation and access to community clinics due to the existing socio-political system of the country. Gender discrimination, religious beliefs and superstitions, male-dominated social structure, and a fragile political culture are obstacles to equal access to the services of the community clinic. Furthermore, rural people receive low quality and a few services from the clinics that cannot meet the needs of the different types of service users within the community. The community clinic provides only some common types of treatment and medicines like panacea due to lack of proficient workforce, medications, and budget. Staffing for the operation of community clinics is much lower than the planned levels. Besides, the skill 
level of the community health care providers is often too small to provide quality services to the community. In each community clinic, the infrastructure and technical facilities are very scanty to arrange quality services. However, the intensive family planning and expanded immunization programs of the CC reduced the maternal and child mortality rate drastically. The decentralized health care system negatively impacts the overall service delivery system of community clinics in Bangladesh. Although community involvement is seen as an effective mechanism for providing better health care services, the CG and CSG do not represent the active participation of the community in the decentralized health care system, as they are selected based on political identity and having no power. Moreover, the provided services and interests of the community clinics are monopolized by the rural local elite, and misaligned responsibilities create contradictions among different levels for making effective coordination.

There are no clear jurisdictional boundaries to ensure accountability and transparency of the community clinics, which lead the health care providers to corruption. The monitoring system is very sluggish and intermittent. The government should buy land in a suitable place to establish the clinic according to the demands of the community. Sufficient medicine and prioritizing budget allocation for the community clinic from the central government is indispensable to improving service delivery provision (Kabir, Huq, Al-Amin, \& Alam, 2012). The government of Bangladesh should provide adequate and appropriate logistical support to each community clinic to promote smooth access to its services (Sarker et al., 2015).

The government should also maintain some intrinsic strategies to increase the availability of MBBS doctors at the local level by providing some incentives to encourage them to stay there. The dissemination of health care information and awareness-building among the local people should be done through social leaders like teachers, imams, and other honorable persons in society, as these leaders can play a vital role in removing existing discrimination and superstition in society. The CG and CSG roles should be filled by people from all strata of society, without considering nepotism and political identity. As the service delivery system of the local areas is strongly linked to central agencies, a "strategic coordination synergy" is imperative to providing quality services. The local authority should have clear responsibility and political power to monitor and supervise the $\mathrm{CC}$. The punishment of the offenders should be very severe, and the other officials should be notified of these decisions. A powerful mobile court should be established to monitor the daily activities of the CC providing with the exclusive power to execute the decision instantly. Gender mainstreaming, social auditing, self-staffing, planning for local development, clear delegation of functions, and communal education can change the existing features of the local healthcare service delivery system. 


\section{Acknowledgment}

I would like to deliberate my nethermost recognition to my supervisor Professor Kristof Titeca, the University of Antwerp-Belgium, for his exquisite instruction, encouragement, and patience, which helped me to acuminate my theoretical knowledge and rational discussion in this paper. His excellent editorial advice has broadened my outlook and directed me to multitudinous lessons on academic research.

\section{References:}

1. Ackataia-Armah, N. M., Addy, N. A., Ghosh, S., \& Dube, L. (2016). Fostering reflective trust between mothers and community health nurses to improve the effectiveness of health and nutrition efforts: An ethnographic study in Ghana, West Africa. Social Science \& Medicine, 158, 96-104.

2. Adato, M., Hoddinott, J., \& Haddad, L. J.(2005). Power, politics, and performance: community participation in South African public works programs (Vol.143): Intl Food Policy Inst.

3. Adeyemo, D. (2005). Local government and health care delivery in Nigeria: a case study. Journal of Human Ecology, 18(2), 149-160.

4. Ahmad, A., Bose, M., \& Persson, T.H. (2007). Decentralized provision of primary healthcare provision in rural Bangladesh: A study of government facilities.

5. Ahmad, I., Yasin, M., Rowshon, A., \& AKM, R. I. (2015). Study on socio-economic and educational condition of tea workers at Sylhet in Bangladesh. Journal of Tea Science Research, 5(5), 15-25.

6. Ahmed, S., Alam, B., Anwar, I., Begum, T., Haque, R., Khan, J., \& Osman, F. (2015). Health systems in transition. Bangladesh Health System Review, 5(3),20-31.

7. Akter, S., Mazumder, M., Alam, M., Pal, N., \& Mozahid, M. (2017). Reproductive dimensions of ethnicity: The present situation of prominent ethnic communities of Sylhet district, Bangladesh. Asian Research Journal of Arts and Social Sciences, 2 (3), 1-8.

8. Aminuzzaman, S. M. (2010). Local government and development in Bangladesh lessons learned and challenges for improving service delivery of union parishad (UP). Local Governance Support ProjectLearning and Innovation Component (LGSP-LIC).

9. Anwar, A., Killewo, J., Chowdhury, M., \& Dasgupta, S. (2005). Bangladesh: Inequalities in utilization of maternal health care services -evidence from Matlab. Reaching the poor with health, nutrition, and population services-what works, what doesn't, and why. Washington, DC: World Bank, 117-136. 
10. Ashaduzzaman, A., Rahman, M., \& Rahman, S. M. (2005). Poor people's access to health services in Bangladesh: Focusing on the issues of inequality. Paper presented at the Network of Asia-Pacific Schools and Institutes of Public Administration and GoverNance (NAPSIPAG) Annual Conference.

11. Bhuiya, I., Rob, U., Chowdhury, A. H., Rahman, L., Haque, N., \& Khan, M. (2004). Impro Ving adolescent reproductive health in Bangladesh.

12. Boris, O. H. (2015). Challenges confronting local government administration inefficient and effective social service delivery: The Nigerian Experience. International Journal of Public administration and Management Research, 2(5), 12-22.

13. Chirenje, L. I., Giliba, R. A., \& Musamba, E. B.(2013). Local communities' participation in decision-making process through planning and budgeting in African countries. Chinese Journal of Population Resources and Environment, 11(1), 10-16.

14. Chowdhury, P., \& Jenkins, A. (2018). Feasibility of solar-biomass hybrid cold storage for un electrified rural areas of Bangladesh. In The Environmental Sustainable Development Goals in Bangladesh (pp. 7384): Routledge.

15. Cooke, B., \& Kothari, U. (2001). Participation: The new tyranny. Zed Books.

16. Creswell, J.W., \& Creswell, J. D. (2017). Research design: Qualitative, quantitative, and mi-xed methods approach. Sage Publications.

17. Day, J., Levett-Jones, T., \& Taylor, A. C. T. (2014). Using a virtual community to enhance nursing student's understanding of primary health care. Collegian, 21(2), 143-150.

18. Deeb-Sossa, N. (2007). Helping the 'neediest of the needy' An intersectional analysis of Moral identity construction at a community health clinic. Gender \& Society, 21(5), 749-772.

19. Douangmala, C. S., Hyden, S. A., Young, L.E., Rho, J., \& Schnepper, L.(2012). Factors influencing healthcare utilization within a free community clinic. Journal of Immigrant and Minority Health, 14(4), 698-705.

20. Fjeldstad, O. H. (2004). Decentralization and corruption: A review of the literature. Chr.Michelen Institute.

21. Foster, K. E. (2005). Clinics, communities, and cost recovery: Primary health care and neoli-eralism in postapartheid South Africa. Cultural Dynamics, 17(3), 239-266.

22. Goodrick, G.K., Kneuper, S., \& Steinbauer, J. R. (2005). Stress perceptions in community clinic: a pilot survey of patients and physicians. Journal of Community Health, 30(2), 75-88. 
23. Haines, A., Sanders, D., Lehmann, U., Rowe, A. K., \& Bhutta, Z. (2007). Achieving childsurvival goals: Potential contribution of community health workers. The Lancet,369(9579), 2121-2131.

24. Hamid, S. A., Sadique, Z., Ahmed, S., \& Molla, A. (2005). Determinants of choice of healthcare providers: evidence from selected rural areas of Bangladesh. Pakistan Jour-nal of Social Science, 3(3), 437-444.

25. Hasan, M. (2012). Quality of primary healthcare services in rural Bangladesh: Patients' perpectives. OIDA International Journal of Sustainable Development,3(8), 69-78.

26. Hossain, M. Z., Ahmed, J.U., \& Rahman, S.T. (2017). Preditors of investment expenditure from forign remittances in the sylhet region of Bangladesh: A household level analysis. Journal of Population and Social Studies, 25(1), 11-25.

27. Islam, A. (2009). Bangladesh health system in transition: Seleted articles. Islam, A., \& Biswas, T. ( 2014). Health system in Bangladesh: Challenegs and opportuniyies. American Journal of Health Research, 2(6), 366-374.

28. Islam, M. N. (2011). An introduction to research methods: A handbook for business \& health reasearch. Dhaka: Mullick \& Brothers, 87-99.

29. Iyngkaran, P., Biddargardi, N., \& Beneby, G. ( 2015). Making sense of health care delivery where does the close to community healthcare worker fit in? The case for congestive heart failure. Indian Heart Journal, 67(3), 250-258.

30. Jacob, T., \& Bernard, C. (2013). Exploring the politics of local participation in rural development projects: Small dams rehabilitation projects in Zimbabwe, Russian Journal of Agricultural and SocioEconomic Sciences, 14(2).

31. Jana, A., \& Harata, N. ( 2016). Provisioning healthcare infrastructure in communities: Empirical evidence from West Bengal, India. Socioeconomic Planning Sciences,54, 37-46.

32. Kabir, M., Huq, M., Al-Amin, A. Q., \& Alam, G.M.(2012). Community participation on health and family planning programs in Bangladesh: The role of education and knowledge on HFP for plummeting pharmaceutical costing. Int.J. Pharmacol, 8,10-20.

33. Kalam, A., \& Parvin, S. ( 2015). Primary healthcare expectations and reality of Bangladesh: A sociological analysis of the selected two rural areas. European Journal of Biology and Medical Sciences Research, 3(2), 25-41.

34. Kouam, C.E., Delisle, H., Ebbing, H.J., \& Ridde, V.( 2014). Perspectives for integration into the local health system of community- 
based management of acute malnutrition in children under five years: A qualitative study in Bangladesh. Nutrition Journal, 13(1), 22-32.

35. Lewis, M. (2006). Governance and corruption in public healthcare systems. Center for Global Development Working Paper (78).

36. Mansuri, G., \& Rao, V. (2013). Can participation be induced? Some evidence from developing countries. Critical Review of International Social \& Political philosophy, 16(2), 284-304.

37. March, S., Torres, E., Ramos, M., Ripoll, J., \& Liull, M. (2015). Adult community health-promoting interventions in primary healthcare: A systematic review. Preventive Medicine, 76, S94-S104.

38. Martinez-Vazquez, J. (2011). The impact of fiscal decentralization: Issues in theory and challenge in practice: Asian Development Bank.

39. Mashego, T, A., \& Peltzer, K. (2005). Community perception of quality of primary healthcare services in rural area of Limpopo province, South Africa: A qualitative study. Curationis, 28(2), 13-21.

40. Mohammad, S. (2010). People's participation in development projects at grass-root level: A case study of Alampur and Jagannathpur Union parishad. Unpublished master Thesis, Master of Public Policy and Governance, North South University.

41. MOHFW (2016). Community-based healthcare, ministry of health and family welfare. Retrieved from www.communityclinic.gov.bd/index.php.

42. Munns, A., Forde, K. A., Krouzecky, M., \& Shields, L. (2015). Rainbows: A primary healthcare initiatives for primary scholls. Collegian, 22(2), 153-160.

43. Normad, C., Iftekar, M.H., \& Rahman, S. A. (2002). Assessment of the community clinics: Effects on service delivery, quality and utilization of services. Health Systems Development Program.

44. O’Malley, A.S., \& Forrest, C. B. (1996). Continuity of care and delivery of ambulatory services to children in community health clinics. Journal of Community Health, 21(3), 159-173.

45. O’Malley, A.S., \& Mandelblatt, J. (2003). Delivery of preventive services for low-incomepersons over age 50: A comparison of community health clinics to private doctors' offices. Journal of Community Health, 28(3), 185-197.

46. Okwaro, F.M., Chandler, C.I., Hutchinson, E., Nabirye, C., \& Staedke, S.G.(2015). Challenging logic of complex intervention trials: Community perspectives of a healthcare improvement intervention in rural Uganda. Social science and Medicine, 13, 10-17.

47. Pandy, P. K.(2011). Local government system in Bangladesh: How far is it decentralized? Lex Localis-Journal of Local Self-Government, 9(3), 11-20. 
48. Pradeep, H. (2011). Challenges of local government service delivery: A case study of Matara Municipal Council. Unpublished $\mathrm{PhD}$ dissertation, NSU: NOMA MPPG Program.

49. Premkumar, R., Pothen, J., Rima, J., \& Arole, S. (2016). Prevalence of hypertension andprehypertension in a community-based primary healthcare program villages at central India. Indian Heart Journal, 68(3), 270-277.

50. Sarker, M.A., Harun-or-Rashid, Islam, M., \& Hamajima, N. (2015). Associations of socioeconomic determinants with community clinic awareness and visitation among women: Evidenace from Bangladesh demographic and health survey-2011. BMC Research Notes, 8(1), 590.

51. Scott, Z. (2009). Decentralization, local development and social cohesion: An analytical review. GSDRC Research Paper, 5.

52. Seddiky, A. (2019). Local government and key challenges of service delivery system: Experience from healthcare provision of Bangladesh. Journal of Emerging Trends in Economics and Management Sciences, 10(1), 1-11.

53. Seddiky, A, Ara, E., \& Yasmin, S. (2014). Role of union information and service centre(UISC) to promote healthcare facilities for the rural poor in Bangladesh. AIJRHASS,8(2), 201-210.

54. Silver, A., Figge, J., Haskin, D., \& O’Brien, M.J. (2011). An asthma and diabetes qualityimprovement project: Enhancing care in clinics and community health centres. Journal of Community Health, 36(2), 180-190.

55. Sultana, N, \& Tania, F. (2015). Effectiveness of community clinics in urban area: A cross sectional study. Malaysian Journal of Medical and Biological Research , 2(1), 43-48.

56. Transparency International (2009). Corruption and local government: The global coalitationagainst corruption. What to do and what not to do.Retrieved

from http://www.trnparency.org/whatwedo/publication/working_paper_05 _2009_corruption_and_local_government.

57. Vander Hoeven, M., Kruger, A., \& Greeff, M. (2012). Differences in healthcare seeking behaviour between rural and urban communities in South Africa. International Journal for Equity in Health, 11(1), 31.

58. Wilkinson, R.G.(1997). Socioeconomic determinants of health, Health inequalities: Relative or absolute material standards? BMJ, 314 (7080), 591. 